\title{
SHOCK INDUCED FLUID-STRUCTURE INTERACTION ON A FLEXIBLE WALL IN SUPERSONIC TURBULENT FLOW
}

\author{
S. Willems, A. Gülhan, and B. Esser \\ Supersonic and Hypersonic Technology Department \\ Institute of Aerodynamics and Flow Technology \\ German Aerospace Center (DLR) \\ Linder Höhe, Köln 51147, Germany
}

\begin{abstract}
Since escalating fluid-structure interactions (FSI) can cause a complete loss of a spacecraft, a detailed knowledge of the mechanisms of flowstructure interactions in supersonic flows is important for the design of future space transportation systems. The first step is to analyze the basic mechanisms at a generic test case that is ascertainable also with high quality simulations. Therefore, this work was devoted to the investigation of the shock wave boundary layer interaction on an elastic panel. During the wind tunnel experiments, the panel deflection was measured with fast nonintrusive displacement sensors. On the flow side pressure, high-speed Schlieren photography and oil-film technique were used. The flow manipulation due to the panel deflection becomes manifest in a deformation of the impinging shock and the separation zone. The panel deflection consists of a constant and a dynamic component. The experimental results are discussed and compared to numerical results.
\end{abstract}

\section{INTRODUCTION}

The design of a propulsion unit is one of the driving parameters of the costs and reliability of future space transportation systems. A design approach based on experiments is not feasible because of the high costs of construction, manufacturing and testing. Therefore, the development of reliable numerical tools is important for the design and optimization. But such tools have to include several complex flow and structure properties such as; real gas effects, multiphase flow, base flow, regenerative and film cooling, structure deformation and degeneration, anisotropic materials, flow separation, and shock wave-boundary layer interaction (SWBLI). The objective of the collaborative research program 
"Transregio 40" is to combine and improve the tools and approaches of the different disciplines for a proper integrated interdisciplinary design process. Beside the numerical projects, the program includes also several experimental projects for the verification of developed physical models and numerical tools. This requires deepening of the comprehension of key mechanisms and the invention of new models. A key factor for the nozzle design is the comprehension of the fluid structure interactions in supersonic flows $[1,2]$. Therefore, it was the topic of several numerical $[3,4]$ and experimental investigations $[5,6]$.

The wind tunnel experiments performed at the Supersonic and Hypersonic Technology Department of the German Aerospace Center (DLR) in Cologne with a generic model and well defined boundary conditions allow the comparison with high order numerical simulations. The experimental setup includes the fundamental and well reviewed problem of a shock wave impingement on the turbulent boundary layer of a flat plate [7-9] and extends it by using an elastic panel allowing two-dimensional (2D) deformation. It combines the aspects of compressibility, flow separation, turbulence and aeroelasticity. In order to detect the influence of the interaction and to facilitate the validation of the numerical tools, the structure deformation and the shock wave boundary layer interaction were also examined separately.

During the experiments, the flow parameters were measured with standard techniques such as pressure sensors, high-speed Schlieren photography and oilfilm technique. The panel deflection was measured via nonintrusive displacement sensors. For a detailed knowledge of the inflow parameter, the turbulent intensity and the boundary layer profile were measured with a Laser-2-Focus Velocimeter and a miniature Pitot rake, respectively.

This paper presents the main results of the experiments combining an SWBLI with an FSI and comparing them with some numerical simulations.

\section{EXPERIMENTAL SETUP}

\subsection{The Model}

The generic model used for the experiments was designed for the research into fluid structure interactions and the verification of coupled flow-structure simulations. The requirements include well defined boundary conditions, a nonintrusive but fast measurement of the flow and the structural characteristics, a flexible setup for sensitivity analysis and the possibility to break a complex flow-structure interaction down to the basic effects. In addition, it should be (distantly) related to the situation of an overexpanded nozzle flow with a capshock and thereby induced separation on the nozzle wall [10].

The experiment setup is shown in Fig. 1a. It consists of a quadratic base plate 1 that spans the whole wind tunnel width. It has a sharp leading edge with 

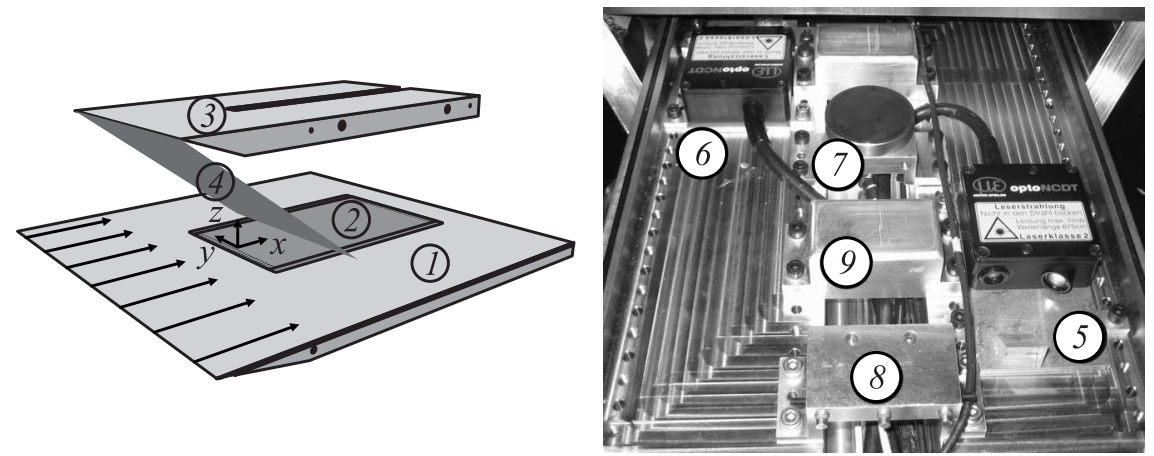

Figure 1 Experimental setup and instrumentation: (a) main model parts; and (b) sensors underneath the panel

a 10 degree ramp angle to the bottom side. A 5-millimeter wide stripe of F150macrogrits $(\approx 60$-micron grains) behind the leading edge trips the boundary layer (see also subsection 3.1). A frame is inserted into the base plate, which carries an elastic sheet metal 2 made of $1.47 \mathrm{~mm}$ thick spring steel (CK 75). Two rows of rivets at the front side as well as at the rear side of the panel realize restrictive grips. The other two sides of the panel are not restricted. A thick layer of a soft type foam rubber between the underside of the elastic panel and a frame's ledge seals the chamber underneath the elastic panel towards the flow. The pressure equalization of this chamber was initially done at a point downstream of the plate where the pressure is similar to the static pressure of the inflow and later at a feed-through in the wind tunnel wall upstream the model. Above the plate, there is a $20^{\circ}$ wedge 3 , which generates a shock 4 that hits the elastic panel. The wedge is $300 \mathrm{~mm}$ wide and its position can be varied in flow direction. For the examination of the SWBLI without a structural deflection, a rigid insert can be mounted into the base plate. The origin of the coordinate system used in this paper is the midpoint of the leading grip's edge. The $X$-axis is defined in flow direction and the $Z$-axis is defined orthogonal to the base plate upwards (see Fig. 1a).

\subsection{Test Facility}

The experiments were carried out in the Trisonic Test Section (TMK) in Cologne. It is a blow down wind tunnel with a closed test section of $0.6 \times 0.6 \mathrm{~m}$. A continuously adjustable nozzle enables the complete Mach number range from 0.5 to 5.7. An ejector allows experiments with reduced static pressure. Thus, the unit Reynolds number can be varied between $7 \cdot 10^{6} 1 / \mathrm{m}$ and $43 \cdot 10^{6} 1 / \mathrm{m}$ at 
Table 1 Free flow parameters of the experiments with unit Reynolds number $\operatorname{Re}_{u}$ and point of impact $x_{\perp}$, boundary layer thickness at point of impact $\sigma_{99 \perp}$, shock angle at impact $\beta_{\perp}$, interaction length $L$

\begin{tabular}{rcrrrrrrrr}
\hline \multirow{2}{*}{$\mathrm{Ma}$} & $\begin{array}{c}p_{\text {ejector }}, \\
\mathrm{MPa}\end{array}$ & $\begin{array}{r}p_{\infty}, \\
\mathrm{kPa}\end{array}$ & $\begin{array}{c}T_{\infty}, \\
\mathrm{K}\end{array}$ & $\begin{array}{c}v_{\infty}, \\
\mathrm{m} / \mathrm{s}\end{array}$ & $\begin{array}{c}\mathrm{Re}_{u}, \\
10^{6} / \mathrm{m}\end{array}$ & $\begin{array}{c}x_{\perp}, \\
\mathrm{mm}\end{array}$ & $\begin{array}{c}\sigma_{99 \perp}, \\
\mathrm{mm}\end{array}$ & $\beta_{\perp}$ & $\begin{array}{c}L, \\
\mathrm{~mm}\end{array}$ \\
\hline 2.5 & - & 21.5 & 127.8 & 566 & 37.0 & 61 & 3.3 & $41^{\circ}$ & 34 \\
3.0 & - & 15.9 & 102.1 & 608 & 45.6 & 112 & 4.6 & $32^{\circ}$ & 33 \\
3.5 & - & 12.0 & 82.6 & 637 & 55.4 & & & & \\
4.0 & - & 9.1 & 68.6 & 664 & 65.2 & 199 & 4.4 & $23^{\circ}$ & 25 \\
4.5 & - & 7.1 & 56.5 & 678 & 77.6 & 228 & 4.5 & $22^{\circ}$ & 0 \\
3.0 & 1.0 & 10.0 & 98.3 & 596 & 45.6 & 112 & 4.0 & $32^{\circ}$ & 33 \\
\hline
\end{tabular}

Mach 3.0. The maximum test time is about $60 \mathrm{~s}$. (For further details, see [11].) The typical test conditions for the Mach numbers used in the experiments are listed in Table 1.

\subsection{Data Acquisition}

The flow parameters of the inflow are recorded by temperature and pressure sensors in the settling chamber of the wind tunnel. Schlieren pictures taken by a Photron FASTCAM APX RS high-speed camera allow a time accurate detection of the shock positions. For most experiments, the image section was $1024 \times$ 512 pixels and the sampling rate $5 \mathrm{kHz}$, for some experiments the section was reduced to $512 \times 256$ pixels to increase the sampling rate to $20 \mathrm{kHz}$. The image analysis was done with the help of the OpenCV library [12] using a Gaussian filter and the Canny edge detection algorithm and is thereby similar to the one described by Estruch et al. [13]. In addition, a software image stabilization algorithm was utilized.

Three pressure sensors (Kulite XTL-DC-123C-190) are placed upstream, downstream and inside the sealed chamber. Underneath the elastic panel there are several displacement sensors (Fig. 1b) to measure the deflection of the elastic panel. Two laser triangulation sensors optoNCDT 1607-10 from Micro-Epsilon 5 and 6 allow point measurements with $10 \mathrm{kHz}$. A capacitive displacement sensor capaNCDT 6350-5 from Micro-Epsilon 7 enables more precise measurements at sample rates up to $50 \mathrm{kHz}$. Three capacitive displacement sensors HPC-75 from Capacitec 8 measure the deflection of the frame at one grip. There are also two pads 9 limiting the maximum deflection to $4.5 \mathrm{~mm}$ and thus avoiding the elastic panel hitting the sensors. To gain more information about the deflection shape, the displacement sensors can be placed at several positions under the panel. 
The static results of the sensors were processed by averaging all data points of $10 \mathrm{~s}$ steady state flow. For the frequency spectra of the sensor measurements and the shock positions, the gained data are divided into several blocks with an overlap of $50 \%$. After multiplying with the Hann function, the power spectral density is processed for each block and then the arithmetic average of all block results is computed.

The oil-film technique [14] was used to determine the shape of the shock boundary layer interaction zone and the size of the recirculation region on the rigid and the elastic panel. For the pure deflection experiments, the elastic panel was equipped with pairs of strain gauges in half bridge configuration. The rigid insert is equipped with two rows of static pressure probes (PSI) every $10 \mathrm{~mm}$. One row is on the symmetry axis and the other one in 90-millimeter distance.

\section{PRELIMINARY EXPERIMENTS}

The preliminary experiments were performed to determine the exact boundary conditions of the test facility and the model. This is important for the comparison with high quality simulations.

\subsection{Flow Characterization}

The turbulent intensity and velocity in the undisturbed inflow were directly measured with a Laser-2-Focus Velocimeter. It measures the point velocity distribution of particles in the flow in a single direction with the help of two focused laser beams as shown in Fig. $2 a$ (for further details, see $[15,16]$ ). Therefore, the flow was seeded with an oil aerosol at the end of the settling chamber. The turbulent intensity $I$ was thereby quantified to a value of $1.9 \%$ in streamwise direction and $2.3 \%$ in orthogonal direction. This matches the estimation for a fully developed pipe flow [17] of $1.9 \%$ for a Reynolds number $\operatorname{Re}_{D_{H}}=29 \cdot 10^{6}$ based on the hydraulic diameter $D_{H}=0.6 \mathrm{~m}$ :

$$
I=\frac{0.16}{\sqrt[8]{\operatorname{Re}_{D_{H}}}} .
$$

The measured velocities in the free flow were about $0.5 \%$ lower than the values calculated with the help of the isentropic equations for a de Laval nozzle. The direct measurement of the velocity profile in the boundary layer was not possible, as there were too few particles. But for the numerical simulations, it was important to guarantee a fully developed turbulent boundary layer and to characterize the boundary layer in detail. Therefore, a miniature Pitot rake was mounted onto a plate with the same shape as the base plate $150 \mathrm{~mm}$ from the tip (which equates $x=-70 \mathrm{~mm}$ ). It has ten tubes with an inner diameter of $0.2 \mathrm{~mm}$ 


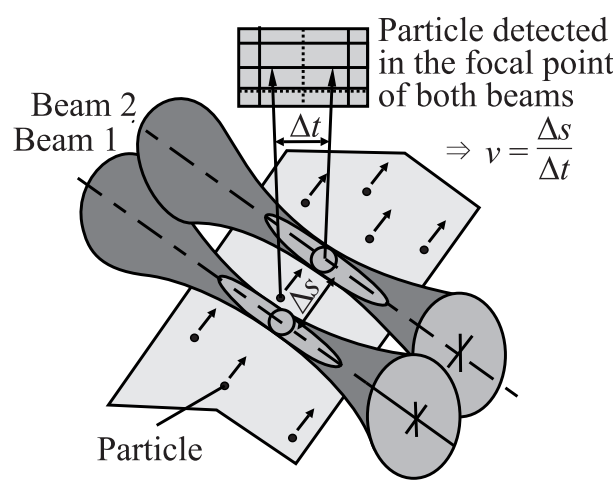

(a)

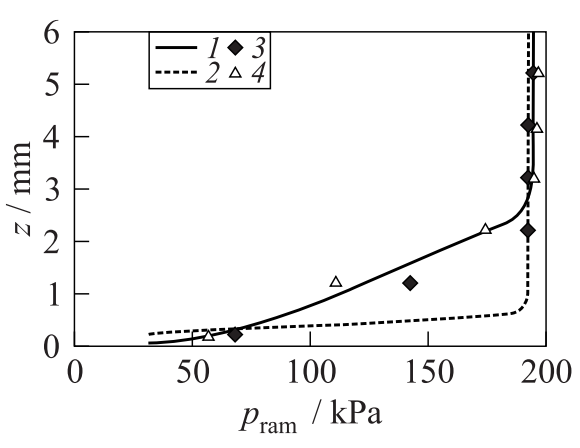

(b)

Figure 2 Experiments for flow characterization: (a) concept draft of the Laser2-Focus velocimeter; and $(b)$ boundary layer characterization at Mach 3.0 and $x$ $=-70 \mathrm{~mm}(1-\mathrm{TAU}$, turbulent; 2 - TAU, laminar; 3 - pitot rake untripped; and $4-$ pitot rake tripped)

and an outer diameter of $0.4 \mathrm{~mm}$. Different types of tripping were tested. The measured ram pressures were compared with the results of simulations with a turbulent and a laminar wall using the numerical flow solver TAU and the Wilcox $-k-\omega$ turbulence model. Figure $2 b$ shows the measured values with and without the selected tripping at the leading edge and the simulation results. The good agreement between the tripped experiment and the turbulent simulation justifies the assumption of a fully turbulent boundary on the complete plate while using the tripping.

\subsection{Structural Behavior Under a Static Uniform Load}

To determine the pure deflection characteristic of the elastic panel additional experiments with a static uniform pressure load were performed. Therefore the pressure underneath the elastic panel was reduced. The deflection at the panel's center against the pressure difference is plotted in Fig. $3 a$. For the discussion of the additional numerical results, see subsection 4.1. Figure $3 b$ shows the measured deflection of the frame were the elastic panel is fixed. Obviously, the grip is not ideally restrained, but there is a repeatable measurable deflection.

To gain more information about the deflection, the tensile strain in the elastic panel was measured at several positions with the help of strain gauges. The measured tensile strain against the deflection is plotted in Fig. $4 a$. The positions and the orientation of the strain gauge pairs are also shown. The sensors 1-3 are placed on the longitudinal symmetry plane and measure in the longitudinal 


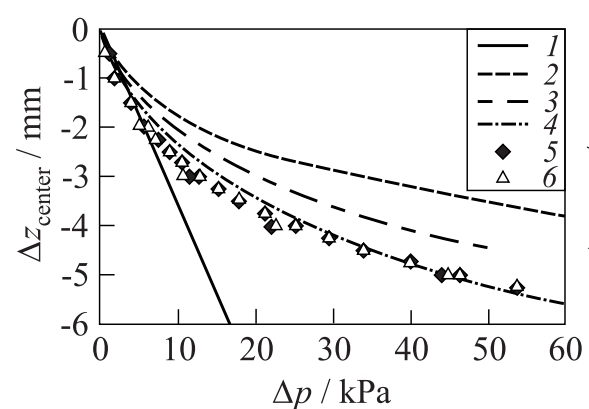

(a)

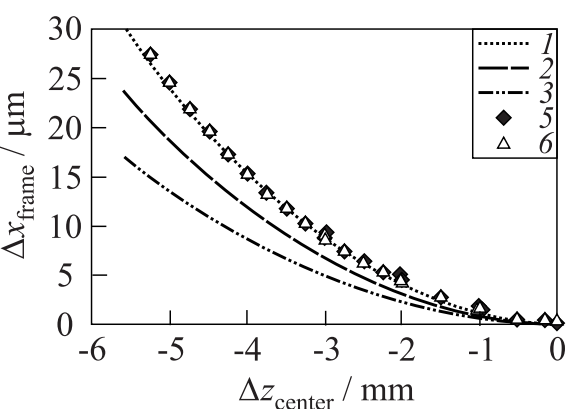

(b)

Figure 3 Deflection of the elastic panel due to a static uniform load: $(a)$ deflection of the panel vs. pressure difference $(1-$ first-order beam equation; 2 - second-order beam equation; 3 - Ansys 3D without rivets; 4 - Ansys 3D with rivets); and ( $b$ ) deflection of the grip vs. deflection of the panel (Ansys 3D with rivets at $z=-7$ (1); -9 (2); and $-11 \mathrm{~mm}(3))$. Signs refer to experiments 1 (5) and $2(6)$

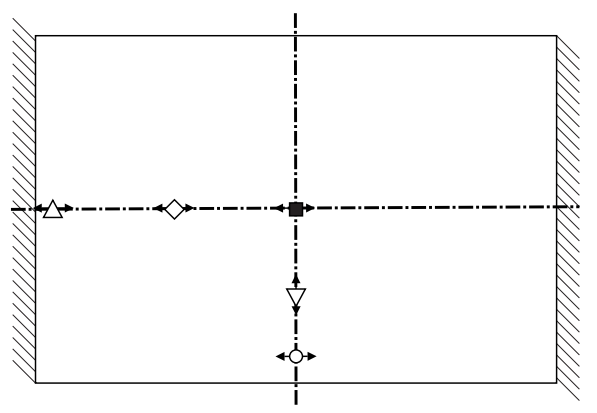

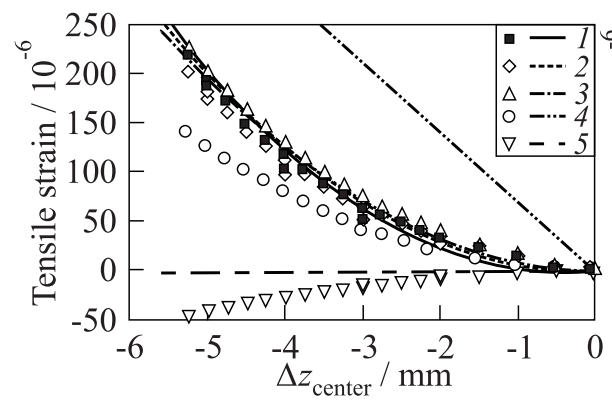

(a)

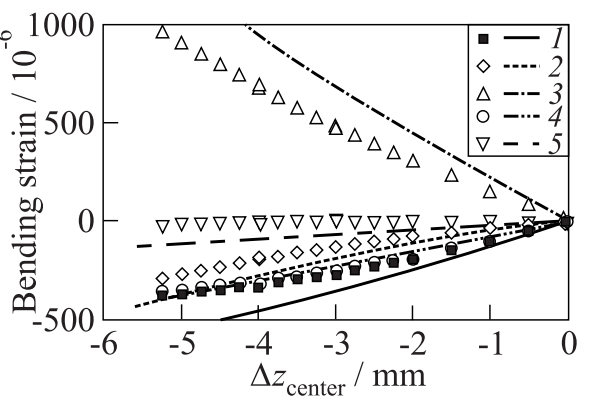

(b)

Figure 4 Tensile $(a)$ and bending $(b)$ strains of the panel vs. deflection of the panel. Curves refer to simulation and signs refer to experiments: $1-x=150 \mathrm{~mm}$ and $y=0 \mathrm{~mm} ; 2-x=80 \mathrm{~mm}$ and $y=0 \mathrm{~mm} ; 3-x=10 \mathrm{~mm}$ and $y=0 \mathrm{~mm} ; 4-$ $x=150 \mathrm{~mm}$ and $y=-85 \mathrm{~mm}$; and $5-x=150 \mathrm{~mm}$ and $y=-50 \mathrm{~mm} ; 1-4-$ in longitudinal direction and $5-$ in transverse direction 
direction. While 1 is placed right in the middle of the panel, 3 is placed close to the grip and 2 is in the middle between those two. As expected all three measure similar tensile strains, but much less than the strain which can be derived from the curve elongation. The strain gauge pair 4 is placed close to a free side of the panel and also measures in longitudinal direction. There, the tensile strains are significantly lower than in the symmetry plane. Sensor 5 is placed between 1 and 4 and measures the compression in the transverse direction. Figure $4 b$ shows the bending strains at the same positions.

\section{NUMERICAL SIMULATIONS}

The numerical results presented in this paper are not based on the tools developed within the Transregio 40 and carried out with more simple models and existing tools. The aim was not to perform high quality simulations including all involved effects but to evaluate and explain the experimental results. In addition, the comparison indicates the requirements for numerical simulations and the options of verification. (For detailed information concerning the numerical simulations developed within the Transregio 40 and connected to the presented experiments, refer to Schieffer et al. [18], Grilli et al. [19, 20], and Danowski and Wall [21].)

\subsection{Numerical Simulation of the Structure Deflection}

The first approximation of the structural deflection under a static uniform pressure load gives the second-order beam:

$$
w^{i \nu}(x)=\frac{q(x)+N w^{\prime \prime}(x)}{E I}
$$

where

$$
N=E A \varepsilon=\frac{E A}{l}\left[\int_{0}^{l} \sqrt{1+\left[w^{\prime}(x)\right]^{2}} d x-l\right] .
$$

It relates the fourth derivative of the displacement $w^{i \nu}(x)$ to the distributed load $q(x)$, the Young's modulus $E$, and the second moment of area $I$. In contrast to the linear first-order beam equation, it considers the second derivative of the displacement $w^{\prime \prime}(x)$ and the tensile force $N$, which is derived from the geometric curve elongation $\varepsilon$ and the cross-section surface $A$. The curve elongation is derived from the original panel length $l$ and the arc length of the deflected panel calculated with the first derivative of the displacement $w^{\prime}(x)$. 


\section{$d z / \mathrm{m}$}

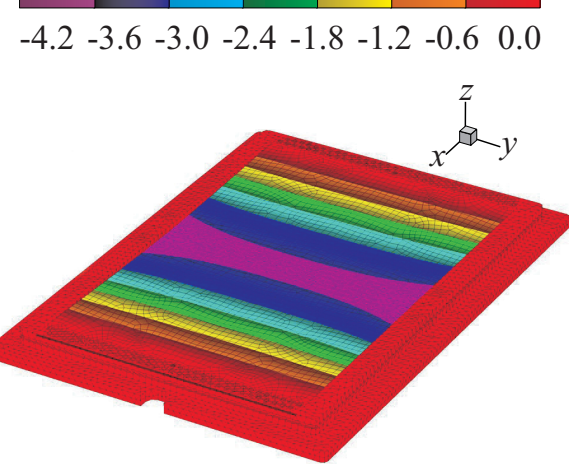

(a)
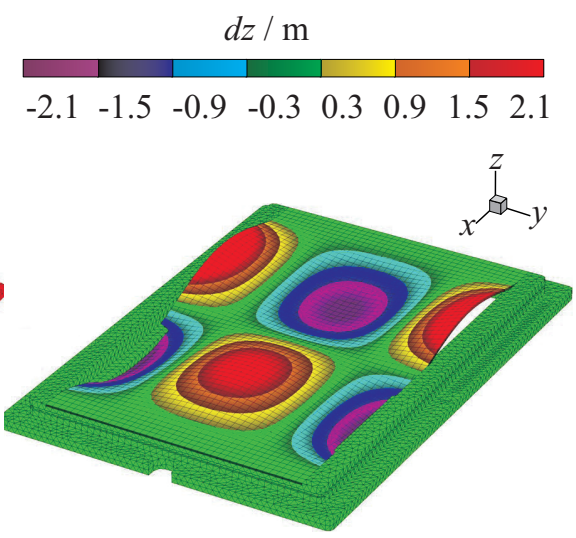

(b)

Figure 5 Three-dimensional finite-element simulation for a static uniform pressure load of $30 \mathrm{kPa}$ : (a) static deflection (with rivets); and (b) normal mode $1 ; 2$ (without rivets).

For a constant distributed load, there is an analytic solution for the second order beam equation but not for the tensile force. The equations are solved numerically in an iterative process, which also allows the use of the realistic pressure distributions of $2 \mathrm{D}$ flow simulations. The results match the results of a 2D finite element simulation using Ansys and regarding nonlinear effects via the option "large deflections." For fast valuable estimations of the panel deflection the second order beam equation can be fitted to the experimental results by multiplying the tensile force with $\left(e^{-7500 \varepsilon}+0.5\right)$.

The results of nonlinear three-dimensional (3D) simulations with Ansys including the frame of the elastic panel are much closer to the measured deflections (see Fig. $3 a$ ). A good coincidence of the simulated and measured deflections at the panel's center can be achieved by replacing the fixed connections between the panel and the frame with modeled rivets. The grids of the 3D Finite-Element Method (FEM) simulations are shown in Fig. 5. The grid without rivets includes the complete panel and frame and has 116 thousand nodes. It is unstructured for the frame and structured for the panel with five equal layers. The grid with rivets involves just one quarter of the panel and frame and has 210 thousand nodes. It is unstructured for both panel and frame but the panel consists of two similar layers. The $3 \mathrm{D}$ simulations predict a greater deflection of the panel at the borders than in the middle. This is shown in Fig. $5 a$ for a static uniform pressure load of $30 \mathrm{kPa}$. The trends of the measured and the simulated deflection of the frame are comparable as it is shown in Fig. $3 b$. But although the center of the sensor is at $z=-11 \mathrm{~mm}$ and the upper edge at $z=-9 \mathrm{~mm}$, the measured 
Table 2 Frequencies of the first normal modes of the elastic panel with an uniform pressure load

\begin{tabular}{|c|c|c|c|c|c|c|c|c|c|c|c|c|c|c|c|}
\hline \multirow{2}{*}{$\begin{array}{l}\Delta p, \\
\mathrm{kPa}\end{array}$} & \multirow{2}{*}{$\begin{array}{c}\Delta z_{\max } \\
\mathrm{mm}\end{array}$} & \multicolumn{14}{|c|}{ Normal modes, $\mathrm{Hz}$} \\
\hline & & $0 ; 0$ & $0 ; 1$ & $1 ; 0$ & $0 ; 2$ & $1 ; 1$ & $1 ; 2$ & $2 ; 0$ & $2 ; 1$ & $0 ; 3$ & $2 ; 2$ & $3 ; 0$ & $1 ; 3$ & $3 ; 1$ & $3 ; 2$ \\
\hline 0 & 0.0 & 88 & 123 & 242 & 284 & 294 & 471 & 475 & 534 & 626 & 730 & 785 & 807 & 850 & 1058 \\
\hline 2 & -0.7 & 96 & 130 & 246 & 291 & 298 & 474 & 482 & 541 & 629 & 734 & 789 & 809 & 856 & 1063 \\
\hline 10 & -2.1 & 154 & 187 & 282 & 342 & 332 & 499 & 528 & 587 & 659 & 770 & 834 & 828 & 905 & 1104 \\
\hline 20 & -3.0 & 197 & 231 & 317 & 388 & 365 & 528 & 571 & 631 & 688 & 804 & 880 & 850 & 953 & 1144 \\
\hline 30 & -3.6 & 226 & 263 & 345 & 422 & 392 & 552 & 604 & 663 & 711 & 831 & 918 & 868 & 992 & 1177 \\
\hline
\end{tabular}

values match those of the simulation at $z=-7 \mathrm{~mm}$. This can be explained either with an error of the frame stiffness in the simulation or with an error of the sensors due to the nonparallel target in the experiment. The simulated tensile and bending strains in the symmetry plane in $X$-direction agree well with the measurements. But the the strains in $Y$-direction and at the border of the panel significantly differ.

The full 3D finite-element model allows an estimation of the normal modes of the elastic panel for various deflections. Ansys performs the modal analysis, based on the prestressed model from the static analysis. As is generally done, the modes are named by the number of neutral lines in longitudinal ( $X$-direction) and transverse direction ( $Y$-direction). Figure $5 b$ shows the normal mode $1 ; 2$ for the static pressure load of $30 \mathrm{kPa}$. The frequencies of the first normal modes for several deflections are given in Table 2. As expected, the frequencies of the normal modes increase with the deflection. But the amount of the frequency increase depends on the mode. In general, the relative frequency increase is bigger for lower modes. Therefore the order of the normal modes regarding their frequency is not constant. For example, in the case of no or just slight deflection $(\Delta p \leq 2 \mathrm{kPa})$, the frequency of the mode $0 ; 2$ is lower than mode $1 ; 1$ and the frequency of the mode $3 ; 0$ is lower than mode $1 ; 3$, but for bigger deflections $(\Delta p \geq 10 \mathrm{kPa})$, it is just the other way round.

\subsection{Numerical Simulation of the Flow Field}

To test the feasibility of the experiments for code verifications and for preliminary comparisons, 2D and 3D simulations with an even and an a priori deflected panel were performed using the numerical flow solver TAU $[22,23]$. The used grids are hybrid grids with semistructured layers close to surfaces and unstructured cells for the rest of the flow domain. The finest $2 \mathrm{D}$ grid has 387 thousand points and the finest 3D grid has 18 million points. Both were a priori refined in the shock and separation regions based on the results of simulations on coarser grids. The $2 \mathrm{D}$ grid was also refined via the automated grid adaptation of TAU. 
For the $2 \mathrm{D}$ grid, this leads to a resolution around $0.1 \mathrm{~mm}$ in the separation regions and even below in the shock regions. The resolution of the shock and separation regions of the $3 \mathrm{D}$ simulations is around $0.5 \mathrm{~mm}$. For all equations of the $2 \mathrm{D}$ simulations and of the $3 \mathrm{D}$ simulation with the standard Wilcox turbulence model, the second order upwind scheme AUSMDV was used for the discretization of the convective fluxes. Due to performance reasons, the other $3 \mathrm{D}$ simulations used a central discretization of the main flow equations and the second-order upwind scheme of Roe for the turbulence equations [24]. The inflow conditions base on the values measured during the experiments, and all walls are modeled as adiabatic walls with a turbulent boundary layer. On the one hand, the results of the simulations show the high dependency of the prediction of the separation bubble at the shock impingement to the turbulence model used. On the other hand, the results show that $2 \mathrm{D}$ simulations are good for first approximations, but high quality simulations have to be $3 \mathrm{D}$.

Figure $6 a$ shows several pressure distributions of the shock wave boundary layer interaction processed by 2D Reynolds-averaged Navier-Stokes (RANS) simulations with different turbulence models and the pressure distributions in the symmetry plane of the analogue $3 \mathrm{D}$ simulations. Figure $6 b$ shows pressure distributions based on $3 \mathrm{D}$ simulations and experimental data in the symmetry plane and in 90-millimeter distance. All simulations predict a major pressure jump at $x=100 \mathrm{~mm}$ caused by the impinging shock wave and a smaller pressure increase in front caused by the separation bubble. The size of the predicted separation and the height of the pressure jump depend on the turbulence model used and on whether the simulation is $2 \mathrm{D}$ or $3 \mathrm{D}$. The separation bubble is smaller for $3 \mathrm{D}$ simulations, but the pressure jump is higher. As the ramp of the wedge is just $30 \mathrm{~mm}$ high and followed by a plane parallel to the base plate, the shock wave is followed by expansion waves. This leads to a pressure decrease after the pressure jump. The intention of this design was to restrict the high pressure loads on the elastic panel to the region of the fluctuating separation bubble and, therefore, to increase the dynamic component of the flow-structure interaction. The decrease is the same for all turbulence models but differs for 2D and 3D simulations.

The two major 3D effects of the shock wave boundary layer interaction are caused by the wedge not spanning the whole wind tunnel width. The first effect is a bending of the wedge's shock wave in the $Y$-direction as it is shown in Fig. $7 a$ and which leads to the different pressure distributions at different $Y$-positions in Fig. 6b. The second effect is the greater expansion and, therefore, steeper decrease of the pressure behind the shock wave due to a flow around the sides of the wedge. This reveals the comparison of the pressure distributions based on $2 \mathrm{D}$ and $3 \mathrm{D}$ simulations in Fig. $6 a$.

The $2 \mathrm{D}$ and $3 \mathrm{D}$ simulations with an a priori deflected panel already predict the dominant effects of the deflection on the flow, which are confirmed by the experiments later on. Figure 7 shows the shape of the separation bubble for a (maximum) deflection of 5 and $3 \mathrm{~mm}$, and the undeflected case based on a 


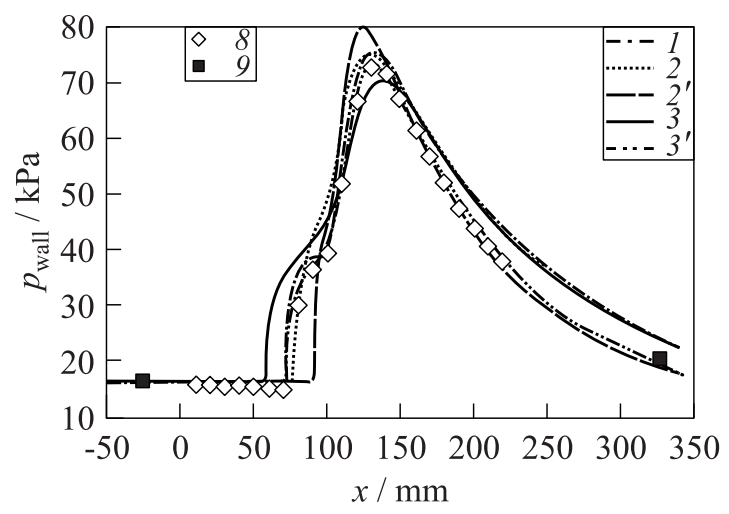

(a)

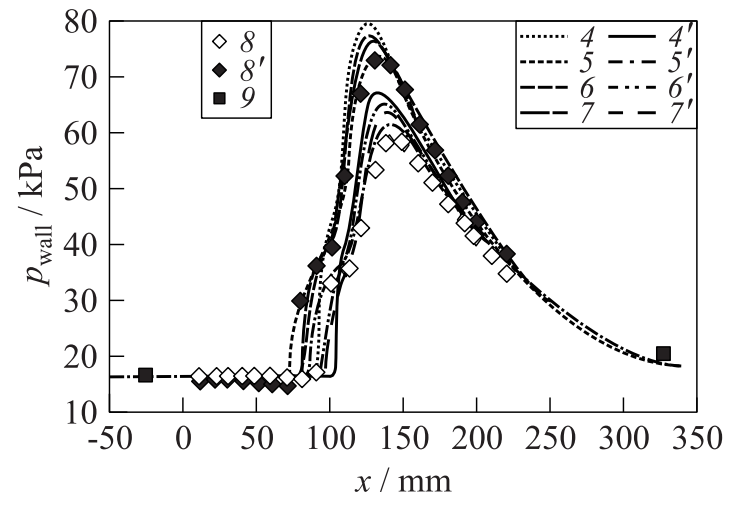

(b)

Figure 6 Pressure distribution of the SWBLI on a rigid panel at Mach 3.0: 1 TAU 2D SAE; 2 - TAU 2D Wilcox; $2^{\prime}-$ TAU 3D Wilcox, $y=0 \mathrm{~mm} ; 3-$ TAU 2D RSM; $3^{\prime}$ - TAU 3D RSM, $y=0 \mathrm{~mm} ; 4$ and $4^{\prime}-$ Wilcox at $y=0$ and $90 \mathrm{~mm}$, respectively; 5 and $5^{\prime}-\mathrm{RSM}$ at $y=0$ and $90 \mathrm{~mm}$, respectively; 6 and $6^{\prime}$ - Wilcox SST (shear-stress transport) at $y=0$ and $90 \mathrm{~mm}$, respectively; 7 and $7^{\prime}$ - Menter SST at $y=0$ and $90 \mathrm{~mm}$, respectively; 8 and $8^{\prime}$ - PSI at $y=0$ and $90 \mathrm{~mm}$, respectively; and 9 - Kulite at $y=0 \mathrm{~mm}$. Signs refer to experiments

2D simulation using a Wilcox $-k-\omega$ turbulence model. Obviously, the separation bubble grows in length and height. In the background, the Mach number distribution of the undeflected case is plotted.

Although the grid resolution of the $3 \mathrm{D}$ simulation with a deflected panel is insufficient in the region of the step between panel and the base plate, a straightening of the impinging shock wave can be observed and the formation of a corner vortex at the edge interface of panel and plate suspected. 

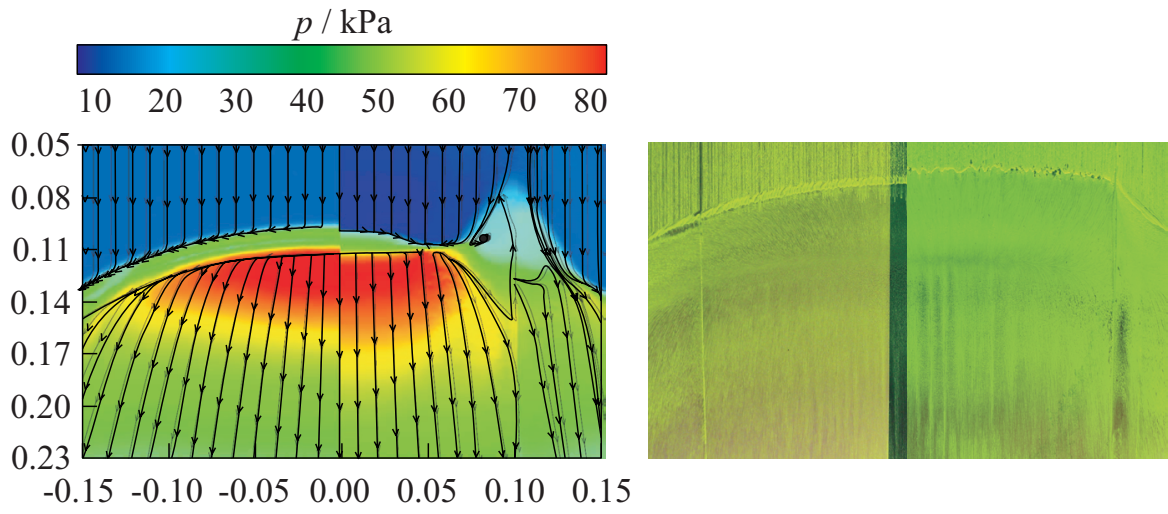

(a)

(b)

Figure 7 Shock shape and separation region at Mach 3.0 on an undeflected and a deflected panel: (a) 3D simulation of stream traces and pressure distribution on an undeflected (left) and an a priori deflected panel (right); and (b) oil-film picture on the rigid (left) and the elastic panel (right).

\section{EXPERIMENTAL RESULTS}

\subsection{Shock Wave-Boundary Layer Interaction on a Rigid Panel}

The main aim of the experiments with a rigid panel was to get a reference state for each Mach number to detect the differences caused by the fluid structure interaction. In addition, any malfunction or interference of the distance sensors due to the vibrations and annoyance of a wind tunnel run could have been identified.

Figure 8 shows a Schlieren photograph of the shock wave boundary layer interaction at Mach 3.0. Easily discernible are the shock wave from the wedge 1, some perturbations from the plate's leading edge 2 , the tripping 3 , and the rivets 4 . At the impingement point a separation bubble forms 6 and the shock is reflected 5 . The expansion waves 7 occurring from the end of the ramp interact with the shock before it impacts on the wall. Obviously, the boundary layer is much thicker after the impingement region 8. Although there is a considerable fluctuation of the separation bubble in the high-speed Schlieren photographs, there is no prominent frequency in the spectrum analysis of the reflected shock position (Fig. 9a) comparable to the ones described by Dupont et al. [8] and Estruch et al. [13]. Beside the frequency axis the diagram also includes an axis with the Strouhal number $S_{L}$, which normalizes the frequency $f$ with the interaction length $L$ and the free stream velocity $u_{\infty}$. Wherein, the interaction length is the distance between the root point of the reflected shock wave and 

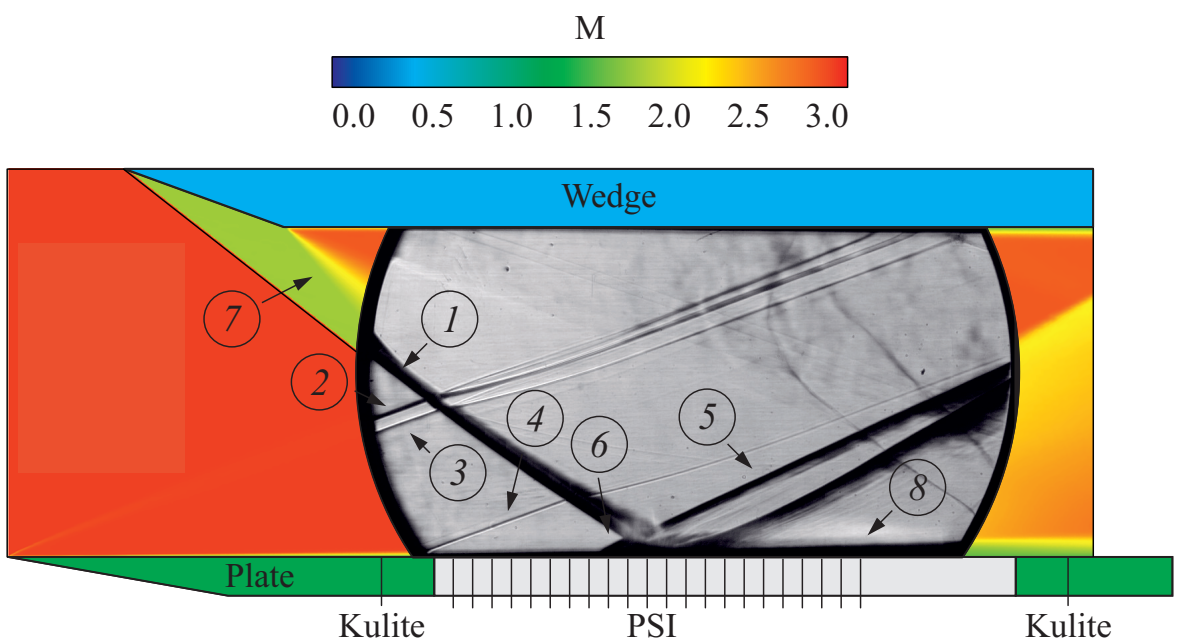

Figure 8 Schlieren photography of the SWBLI at Mach 3.0 in the background the Mach number field of a 2D simulation.

the extrapolated point of impact of the incident shock wave. There are some differences between the spectrum on the rigid and the elastic panel, but as the differences are less than the noise ratio, it is not reasonable to interpret them.

The experiments with a rigid panel allow a precise measuring of the pressure distribution of the shock wave boundary layer interaction. For several Mach numbers, the measured values standardized with static pressure of the inflow (see Table 1) are shown in Fig. $9 a$. The elastic panel would range from $x=0$ to $300 \mathrm{~mm}$. As expected, the smaller the Mach number the earlier the shock hits the panel and the smaller is the relative pressure increase. But with respect to the static pressure values, the absolute pressure increase is bigger for smaller Mach numbers. The use of the ejector allows a reduction of the pressure level and therewith a reduction of the Reynolds number. But this does not change the shock position or the relative pressure increase. The PSI measurements at $y=90 \mathrm{~mm}$ reveal a shift of the interaction region and a lower pressure increase compared to the symmetry plane.

The oil-film method facilitates a closer look on the flow topology in the region of the shock wave boundary layer interaction. On the left side of Fig. $7 b$, the situation on the rigid panel is shown. The uniform parallel inflow, the curved shock, the separation region and some structures downstream are visible. In the symmetry plane the separation ranges from $x=71.5 \mathrm{~mm}$ to $x=111.5 \mathrm{~mm}$. These values agree with the measured pressure distributions.

The structure deflection of the FSI experiments divides into a large static deflection and small vibrations. The panel's load and, therefore, the static com- 


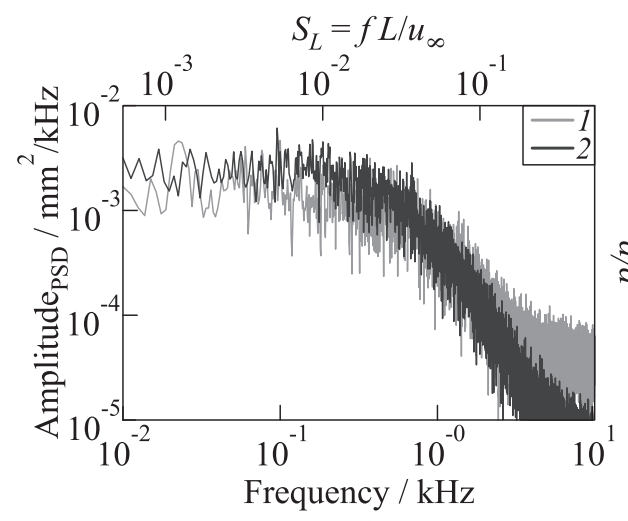

(a)

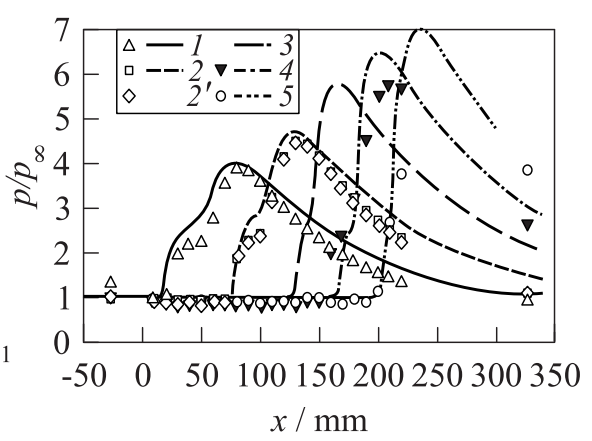

(b)

Figure 9 Experimental results of the SWBLI on a rigid panel: $(a)$ spectrum of the shock movement at 6 (see Fig. 8) - 1 refers to rigid panel and 2 to elastic panel; and (b) measured pressure distributions at several Mach numbers with the flow conditions of Table 1 and corresponding results of $2 \mathrm{D}$ simulations: $1-\mathrm{Ma}=2.5 ; 2-3.0 ; 2^{\prime}-$ 3.0 with ejector; $3-3.5 ; 4-4.0$; and $5-\mathrm{Ma}=4.5$ (curves refer to TAU $2 \mathrm{D}$ and signs to experiments)

ponent of the panel deflection is directly connected to the pressure level of the flow as shown in Fig. 10a. A translational displacement of the wedge is attended by a translational displacement of the shock impingement and the pressure jump and, consequently, a shift of the point of the maximum deflection (Fig. 10c). As a movement downstream reduces the summarized load, it also leads to a reduction of the static deflection. The increase of the Mach number leads to a decreasing pressure level (see Table 1) as well as a shift of the shock impingement downstream (see Fig. 9b). Hence, the maximum deflection decreases and its position moves downstream with an increasing Mach number (Fig. 10e). Figures 10a, 10c, and $10 e$ also include calculations based on the modified second order beam equation as described in 4.1, the pressure distributions from $2 \mathrm{D}$ simulations shown in Fig. $9 b$ and the measured back pressure during the experiments. Figures $10 b$, $10 d$, and $10 f$ show the frequency spectra of the panel deflection measured at the panel's center with the capacitive displacement sensor, which are discussed in subsection 6.3 .

\subsection{Flow-Structure Interaction}

The Mach 3.0 case with the wedge at $x=15 \mathrm{~mm}$ is selected for a more detailed analysis of the frequencies, as it has a relatively small static deflection but large 

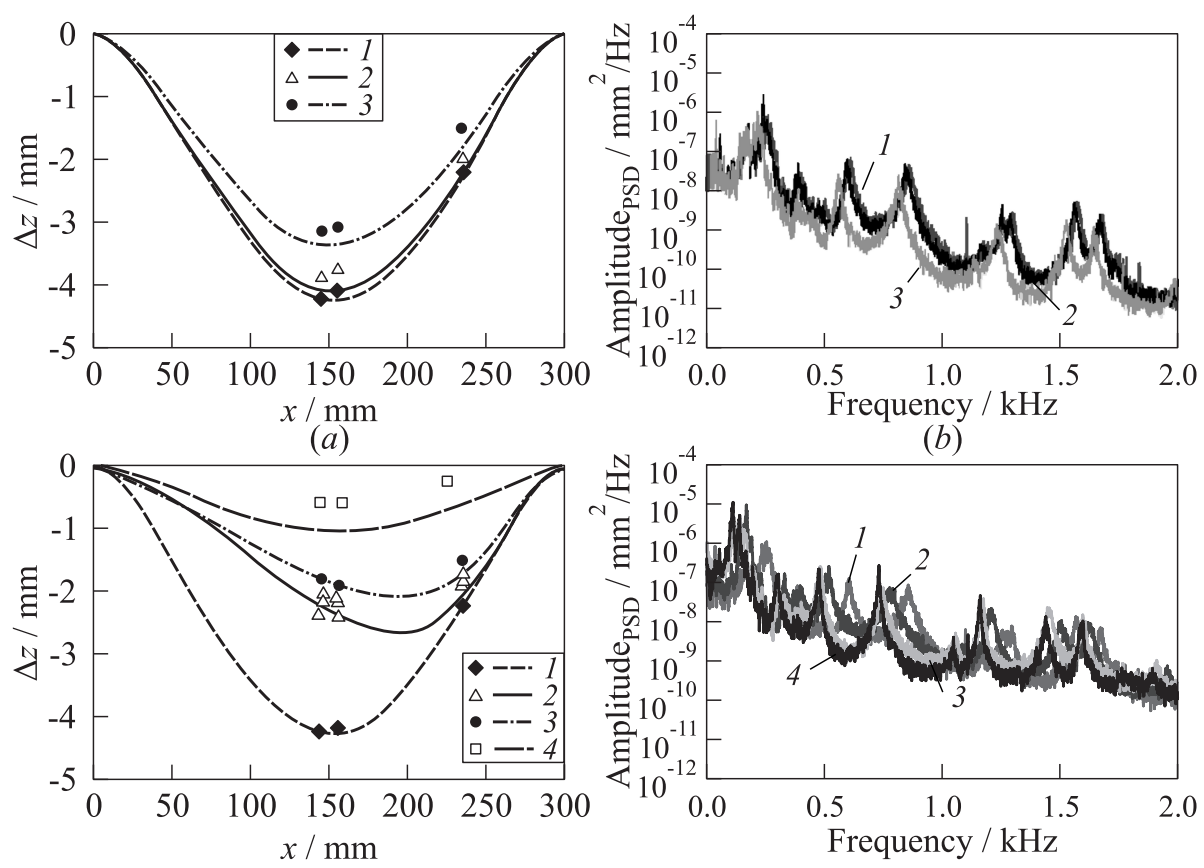

(c)

(d)
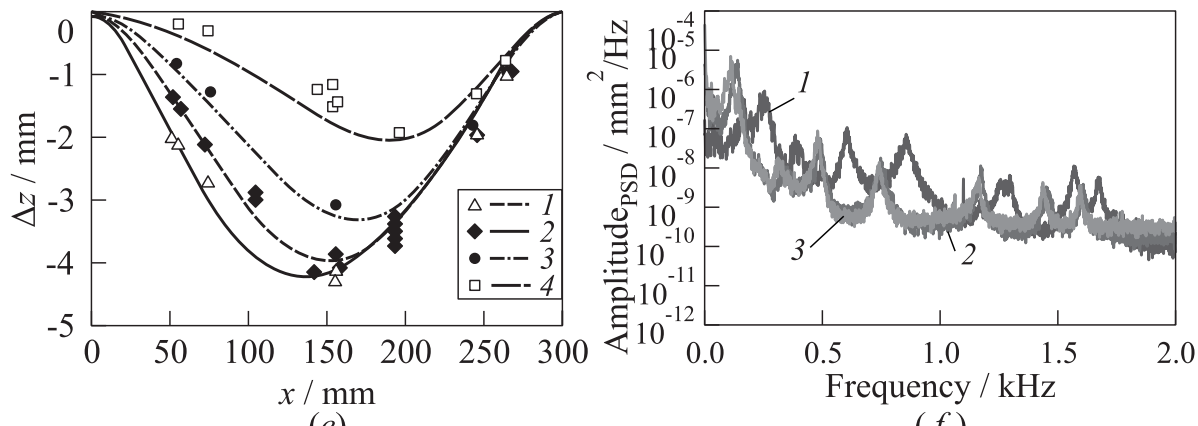

(e)

$(f)$

Figure 10 Deflection of the elastic panel during the wind tunnel experiments: (a) static component for several pressure levels at Mach $3.0(1-15.9 \mathrm{kPa} ; 2-$ 13.8 ; and $3-8.3 \mathrm{kPa}) ;(b)$ spectrum at several pressure levels at Mach $3.0(1-$ $p_{\infty}=15.9 \mathrm{kPa}, \operatorname{Re}_{u}=58.4 \cdot 10^{6} \mathrm{~m}^{-1} ; 2-p_{\infty}=13.8 \mathrm{kPa}, \operatorname{Re}_{u}=50.8 \cdot 10^{6} \mathrm{~m}^{-1}$; and $\left.3-p_{\infty}=8.3 \mathrm{kPa}, \operatorname{Re}_{u}=30.8 \cdot 10^{6} \mathrm{~m}^{-1}\right) ;(c)$ static component for several wedge positions at Mach $3.0(1--160 \mathrm{~mm} ; 2--60 ; 3--35$; and $4-15 \mathrm{~mm})$; $(d)$ spectrum at several wedge positions at Mach $3.0(1--160 \mathrm{~mm} ; 2--60 ; 3--35$; and $4-15 \mathrm{~mm}) ;(e)$ static component for several Mach numbers $(1-2.5 ; 2-3.0 ; 3-$ 3.5 ; and $4-4.0)$; and $(f)$ spectrum at several Mach numbers $(1-3.0 ; 2-4.0$; and 3 - 4.2). Curves refer to solutions of the beam equation (see subsection 4.1) and signs to experiments 
vibrations. The results of the capacitive sensor are analyzed as it has a much lower noise level than the laser triangulation sensors. Due to its size, it can just be placed on the symmetry plane. In two identical runs it was placed once in the middle of the panel $(x=145 \mathrm{~mm})$ and once at three-fourths of the panel length $(x=225 \mathrm{~mm})$. Figure $11 a$ shows a full spectrum of the dynamic component of the structure deflection measured at these positions. There are

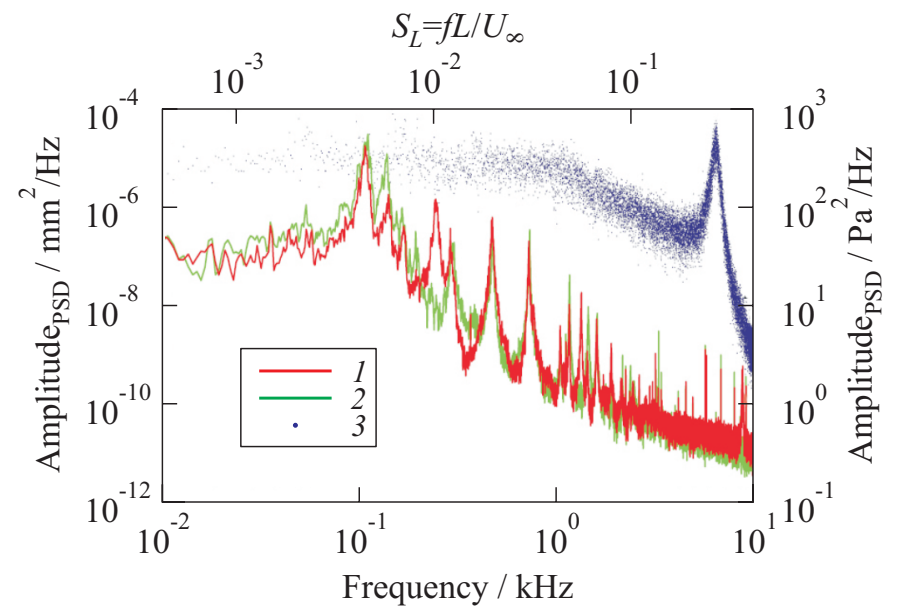

(a)

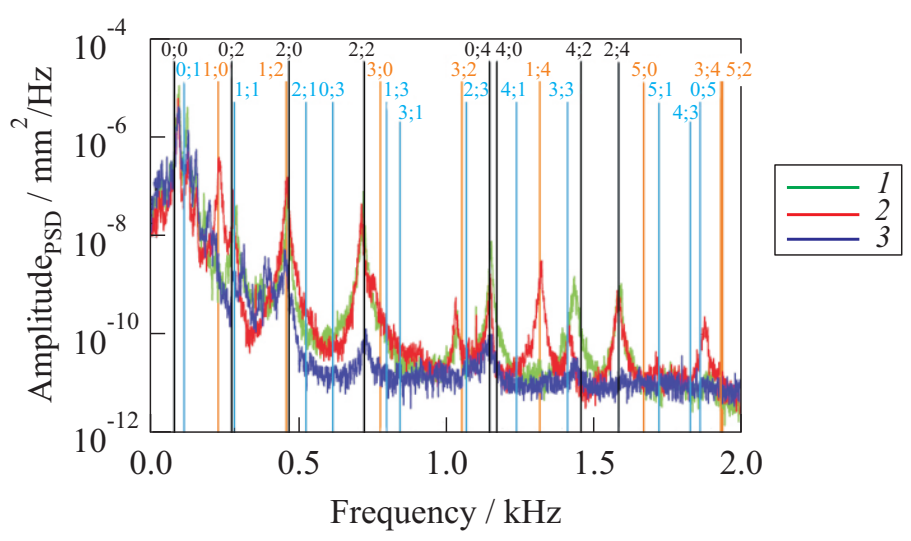

(b)

Figure 11 Measured spectra at Mach 3.0 and the wedge at $x=15 \mathrm{~mm}$ : (a) full spectrum of deflection $(1-x=145 \mathrm{~mm}$ and $2-x=225 \mathrm{~mm})$ and pressure $(3-$ $x=327 \mathrm{~mm}$ ); and $(b)$ vibrational spectrum at two different sensor positions (1 $x=145 \mathrm{~mm}$ and $2-x=225 \mathrm{~mm})$ and without the wedge $(3-x=145 \mathrm{~mm})$. 
several peaks between $50 \mathrm{~Hz}$ and $2 \mathrm{kHz}$ and thus in the range of the normal modes. In addition, there is a single peak at $8.5 \mathrm{kHz}$ for the sensor at position $225 \mathrm{~mm}$.

A detailed look on the panel vibrations in the range of the normal modes gives Fig. 11b. There are several prominent peaks and most of them can be identified as a normal mode of the panel. Therefore, the figure includes also the calculated frequencies for a uniform pressure load of $2000 \mathrm{~Pa}$, which has a comparable deflection. The capacitive sensor cannot detect modes with an odd number in transversal direction (plotted in light blue) as they have a neutral line in the symmetry plane. In addition, it can detect neither modes with an odd number in the longitudinal direction (plotted in orange) if it is placed in the middle of the panel, nor modes with numbers of 3 or 4 in the longitudinal direction, if it is placed at $x=225 \mathrm{~mm}$, as they are also close to neutral lines. The good agreement of the measured peaks and the calculated values becomes especially apparent for the modes $1 ; 0$ and $1 ; 4$ as they are detected just at the nonmiddle position. (This effect does not appear for the modes $1 ; 1$ and $1 ; 3$ as they have an odd number in the transversal direction too or for mode $1 ; 2$ as its frequency is very close to the frequency of mode $2 ; 0$.) In comparison with Vedeneev et al. [6], much more and also higher modes could be surely identified. A detailed discussion of the differences is given in subsection 6.3.

Figure $7 b$ shows an oil-flow picture on the elastic panel. The direct comparison to the rigid panel reveals that the shock on the elastic panel is much less bend. The separation ranges now from $x=63 \mathrm{~mm}$ to $x=113 \mathrm{~mm}$ and is about $25 \%$ longer. In addition, coarser textures downstream the impingement zone are visible.

\section{DISCUSSION}

\subsection{Static and Dynamic Behavior of the Structure}

The investigation of the structure deformation under a static uniform pressure load reveals that in spite of the simple design several effects have to be taken into account for a correct modeling. In contrast to a linear structure model, the second order beam equation considering the geometric hardening gives a reasonable first approximation of the deflection in the symmetry plane. A 3D model including the deformation of the frame which carries the elastic panel and the connecting rivets provides the correct deflections in the middle of the panel and realistic values for the frame deflection.

The simulations as well as the experiments show that the deformation shape of the panel is nearly $2 \mathrm{D}$ with just small variations in the transversal direction. But the measured panel deflections as well as the measured tensile and bending strains (see Figs. $3 c$ and $3 d$ ) indicate an essential difference of the deformation 
shape in the transversal direction compared to the simulations (see Fig. $5 a$ ). In the simulations, the deformation at the free sides is greater than in the middle, whereas it is just the other way around in the experiments. The plausible reason for this is the sealing underneath the borders of the elastic panel, which is not considered in the FEM simulations. In particular, in large deflections, it exerts a force onto the panel due to its compression and this reduces the pressure load at the borders.

As the modal analysis of Fig. $11 b$ is at small panel deflections, the damping effect of the sealing can certainly be neglected. As the frequencies increase with deflection in Figs. 10b, 10d, and 10f, the possible (increasing) damping effect of the sealing is not dominant and does not disturb the trends found out in the analysis of subsection 6.3 .

\subsection{Shock Wave-Boundary Layer Interaction}

The comparison of the measured and computed pressure distributions in Fig. $6 a$ illustrate the sensitivity of this test case to the used turbulence model. There are also big differences between a $2 \mathrm{D}$ simulation and the symmetry plane of a 3D simulation. All 3D simulations catch the pressure decrease behind the shock impingement line much better, as they consider the flow from the wind side to the lee side of the wedge around the side edges. They also catch correctly the shock bending (see Fig. 7a) and, thereby, the delayed pressure increase away from the symmetry plane (see Fig. $6 b$ ). The best agreement with the measured data provides 3D simulations based on the differential Reynolds stress model (RSM) of Eisfeld [25, 26].

As shown in Fig. 9a, the analysis of the high-speed Schlieren pictures did not reveal any prominent frequency as described by Dupont et al. [8] and Estruch et al. [13]. Probably, this is caused by too much low-frequency noise, as the amplitudes decrease for frequencies above $700 \mathrm{~Hz}$, which correspond to the significant Strouhal number of 0.03 found by Dupont. The noise could be caused by vibrations in the Schlieren set-up and a low pixel resolution of the separation bubble. So this should be improved for future test campaigns. As described in subsection 2.1, the boundary layer used for the interaction presented here is freshly made by a flat plate in the free stream. In contrast to that, Dupont and Estruch use the boundary of the wind tunnel wall, which is therefore much thicker, and it might include interferences from upstream. This could also explain the differences. The spectra of the pressure sensors show an unexpected peak around $6.5 \mathrm{kHz}$, which corresponds to a Strouhal number of 0.27 . This peak appears in all experiments with and without a shock impingement and independent from the panel deflection. Although the frequency varies, no clear correlation could be found yet. Unfortunately, it is above the cutoff frequency of the sensor and, therefore, an interpretation would be vague. It is interesting 
that there is also a similar high frequency peak in the panel deflection but at a frequency of $8.5 \mathrm{kHz}$. Unfortunately, this is neither good for a detailed analysis nor measured in the majority of experimental runs, since it disappears when the sensor is placed in the middle of the panel. But future experiments should also investigate this effect.

\subsection{Fluid-Structure Interaction}

The experimental data show that the flow deforms the structure and there is a reaction of the flow to the deflection, hence there is a flow structure interaction.

The constant component of the panel deflection decreases with a decreasing pressure level, a downstream movement of the wedge and an increasing Mach number. The last two also cause a shift of the point of the maximum deflection downstream. Important for this is the total amount and the balance point of the pressure load. An increasing deformation increases also the tensile strains in the panel, which affects the normal modes and thereby the dynamic component of the structure deflection. But there are also some other effects as shown in subsection 5.2. Most of the peaks in the spectrum of the panel deflection directly correspond to a normal mode but some break ranks (see Fig. 11b). The measured frequency of the mode $0 ; 0$ is higher than simulated. This can be explained with the high sensitivity of the mode to the deformation shape. There are differences in the deformation shape between the simulation and the experiment due to the uniform pressure load and not considering the sealing in the simulation. It is striking that a significant frequency shift occurs just for the modes $3 ; 2,4 ; 2$, and $5 ; 2$ and that it is always towards lower frequencies. On the one hand, all these modes have two neutral lines in the transversal direction and, therefore, a connection to the deformation shape seems plausible but, on the other hand, the modes $0 ; 2$ and $2 ; 2$ are not affected.

The comparison of the two spectra in Fig. 11b, with the sensor at the same position, but one with the wedge at $x=15 \mathrm{~mm}$ and one without any wedge, show that the frequencies are nearly the same but the amplitudes differ significantly. This is plausible, as, on the one hand, the deflection is nearly same but, on the other hand, the oscillating separation bubble causes a much higher excitation of the vibrations in the case with the wedge. This effect explains also the difference between Figs. $10 b$ and $10 d$. In both cases most of the flow characteristics as the size and the shape of the separation are unchanged, but the deflection of the panel is reduced in Fig. $10 b$ due to a reduction of the overall pressure level and in Fig. $10 d$ due to a translational displacement of the wedge. Hence, in both cases the frequencies of the normal modes decrease. In the case of the pressure reduction, the amplitudes also decrease, as the excitation through the separation bubble decreases with the pressure level. In contrast to that, in the case of the 


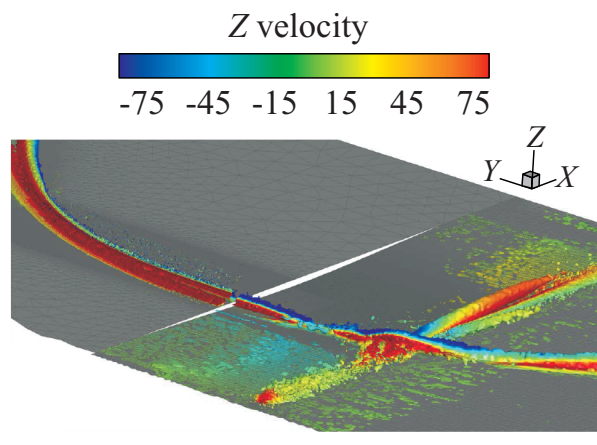

(a)

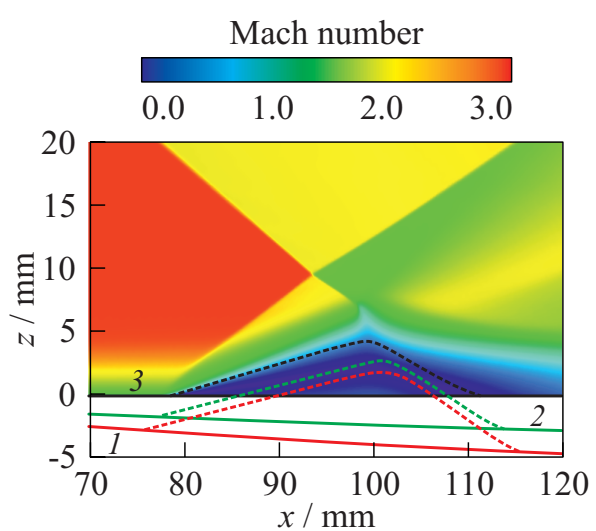

(b)

Figure 12 The computational fluid dynamics results with a priori deflected panels at Mach 3.0 using a Wilcox $-k-\omega$ turbulence model: $(a)$ surfaces of constant $\lambda_{2}$ coloured with the $Z$-velocity for an undeflected panel (top-left) and deflected panel (bottomright); and $(b)$ separation bubble shapes of $2 \mathrm{D}$ simulations with TAU for several defined deflections $(1-3 \mathrm{~mm}$ and $2-5 \mathrm{~mm})$ at Mach 3.0 and the Mach number distribution for the undeflected case (3).

wedge displacement, the amplitudes increase as the excitation is constant but the tensile forces are reduced. As discussed before, an increase of the Mach number also leads to a reduction of the panel deflection and again this leads to a reduction of the frequencies (see Fig. 10f) but this time, the amplitude of some modes increases (1st and 5th) and of some decreases (2nd, 4th, and 6th), and some of the modes are quite the same (3rd and 7 th). This could be caused by a changing excitation due to a changed separation bubble.

The most evident reaction of the flow on the panel deflection is the straightening of the curved shock (see Fig. $7 b$ ). This is probably caused by the corner vortices that arise at the deflected panels border and interact with the shock. There is a step formed between the elastic panel and the surrounding plate, as the elastic panel does not span the whole wind tunnel width. This is visualised by the the surfaces of constant $\lambda_{2}$ in Fig. $12 a$ based on a 3D simulation with TAU. For the change of the separation bubble size, the direct dependency to the static component of the streamwise panel deflection is proven by $2 \mathrm{D}$ simulations as shown in Fig. 12b. Although the size and the position are not predicted correctly (see also subsection 4.2), the enlargements on a priori deflected panels match quite well the measured values. The coarser textures of the oil flow picture on the elastic panel downstream the impingement zone indicate larger structures in the flow, in particular, stationary vortices which is probably also a consequence of the larger separation zone. 


\section{SUMMARY}

An experimental study concerning the fluid structure interaction has been carried out in the supersonic flow regime of the TMK in Cologne. The focus of the investigations was a detailed characterization of the wind tunnel flow as well as a precise measurement of the shock wave boundary layer interaction and the structure deformation. The detailed analysis of the boundary conditions of the experiments provides a reliable basis for the validation of numerical simulations. The combination of an SWBLI with an FSI is challenging for modeling and, therefore, promises to be an adequate criterion.

To facilitate detailed and parametric numerical simulations, one objective of the experimental setup was a $2 \mathrm{D}$ flow-structure interaction. For several reasons, this could not be achieved. The shock generator and the elastic panel of the test model do not span the whole wind tunnel width, which leads to a 3D flow topology in the whole test volume. Because of its finite width and not ideally restrained grips, the panel deformation is also 3D. This leads to more complex measurements, analysis, and simulations.

The measured data confirmed a flow induced structure deformation consisting of a big static component and small dynamic components with several dominant frequencies between 50 and $2000 \mathrm{~Hz}$ corresponding to the normal modes of the deflected panel. Although the amplitudes of the structure oscillation are very small, they showed direct dependencies of the flow on the excitation. For a better understanding of the mechanism and an explanation of some frequency shifts, further detailed analysis is necessary.

Although there is a measurable reaction of the flow to the deformation of the structure the dynamic aspects are not as evident as expected. Surprisingly, no prominent frequencies in the Schlieren pictures were identified and the measured peak in the pressure spectrum is at unexpectedly high frequencies. For a better detection of any changes in the flow properties of future experiments, it is necessary to use faster pressure sensors and to improve the Schlieren photography.

To enhance the fluid structure interaction it is planned to build a new insert which should generate vibrations with larger amplitudes. Therefore, the frequency of one of the first panel's normal modes should coincides with a dominant frequency of the flow, e.g., the separation oscillation.

The numerical simulations of the structure and the flow show that the separated static problems can be adequately computed with advanced but existing simulation tools such as 3D flow simulations with RSM (Reynolds stress model) and $3 \mathrm{D}$ nonlinear structure simulations. The next step is to validate the coupling of structure and flow simulations as well as the time-resolved simulation tools, which are developed within the Transregio $40[18,20]$. High quality simulations and further experiments will support the explanation of several effects of the fluid structure interaction, which were detected in the experiments. 


\section{ACKNOWLEDGMENTS}

This project is financially supported by the German Research Foundation (Deutsche Forschungsgemeinschaft - DFG) within the Transregional Collaborative Research Center 40 (Sonderforschungsbereich Transregio 40). The help and advice of the technical staff of the Supersonic and Hypersonic Technology Department in Cologne is gratefully acknowledged.

\section{REFERENCES}

1. Koschel, W. 2003. Flight 157 - Ariane 5 ECA: Report of the inquiry board. Technical Report. European Space Agency.

2. Hagemann, G. 2009. Shock pattern in the plume of rocket nozzles: needs for design consideration. In: 26th International Symposium on Shock Waves (ISSW). Ed. K. Hannemann. Göttingen. Vol. 17.

3. Lüdeke, H., J. B. Calvo, and A. Filimon. 2006. Fluid structure interaction at the ARIANE-5 nozzle section by advanced turbulence models. In: European Conference on Computational Fluid Dynamics (ECCOMAS CFD). Eds. P. Wesseling, E. Onate, and J. Périaux. Delft: TU Delft.

4. Storti, M. A. N. M. Nigro, R. R. Paz, and L. D. Dalcín. 2009. Strong coupling strategy for fluid-structure interaction problems in supersonic regime via fixed point iteration. J. Sound Vibration 320:859-77.

5. Ruf, J.H., A. M. Brown, and D. M. McDaniels. 2004. Nozzle side load testing and analysis at Marshall space flight center. 45th AIAA/ASME/SAE/ASEE Joint Propulsion Conference. Denver, Colorado: American Institute of Aeronautics and Astronautics.

6. Vedeneev, V. V., S. V. Guvernyuk, A. F. Zubkov, and M. E. Kolotnikov. 2010. Experimental observation of single mode panel flutter in supersonic gas flow. J. Fluids Structures 26(5):764-79.

7. Dolling, D. S. 2001. Fifty years of shock-wave/boundary-layer interaction research: What next? AIAA J. 38(8):1517-31.

8. Dupont, P., C. Haddad, and J. F. Debiève. 2006. Space and time organization in a shock-induced separated boundary layer. J. Fluid Mech. 559:255-77.

9. Humble, R. A., G. E. Elsinga, F. Scarano, and B. W. van Oudheusden. 2007. Investigation of the instantaneous $3 \mathrm{D}$ flow organization of a shock wave/turbulent boundary layer interaction using tomographic PIV. AIAA Paper No. 2007-4112.

10. Reijasse, P., and R. Poutrel. 2005. Flow separation regimes induced by capshock in over-expanded optimized propulsive nozzles. 1st European Conference for Aerospace Sciences (EUCASS). Moscow.

11. Esch, H. 1986. Die 0,6-m X 0,6-m-Trisonische Meßstrecke (TMK) der DFVLR in Köln-Porz (Stand 1986). DFVLR-Mitteilungen. Deutsche Forschungs- und Versuchsanstalt für Luft- und Ramfahrt e.V. Köln. 
12. Bradski, G., and A. Kaehler. 2008. OpenCV: Computer vision with the OpenCV Library. 1st ed. Sebastopol, California: O'Reilly Media.

13. Estruch, D., N. J. Lawson, D. G. MacManus, K. P. Garry, and J. L. Stollery. 2008. Measurement of shock wave unsteadiness using a high-speed schlieren system and digital image processing. Rev. Sci. Instruments 79:(12):126108.

14. Loving, D. L., and S. Katzoff. 1959. The fluorescent-oil film method and other techniques for boundary-layer flow visualization. Technical Report NASA MEMO 3-17-59L.

15. Boutier, A., G. Fertin, and J. Lefevre. 1978. Laser velocimeter for wind tunnel measurements. IEEE Trans. Aerospace Electronic Syst. 14(3):441-55.

16. Schodl, R. 1979. Development of the laser two-focus method for non-intrusive measurement of flow vectors particularly in turbomachines. Ph.D. Thesis ESA-TT-528. Paris, France: European Space Agency.

17. Fluent. 2006. FLUENT 6.3 User's guide. Lebanon, New Hampshire: Fluent Inc.

18. Schieffer, G., N. Hosters, M. Klaus, M. Behr, and H.-G. Reimerdes. 2011. Towards aerothermoelastic simulations of supersonic flow through nozzles. 4th European Conference for Aerospace Sciences (EUCASS). St. Petersburg.

19. Grilli, M., S. Hickel, and N.A. Adams. 2011. Implicit large eddy simulation of a supersonic turbulent boundary layer over a compression-expansion ramp. 4th European Conference for Aerospace Sciences (EUCASS). St. Petersburg.

20. Grilli, M., N. A. Adams, S. Willems, and A. Gülhan. 2012. Experimental and numerical investigation on shockwave/turbulent boundary layer interaction. 42nd AIAA Fluid Dynamics Conference and Exhibit. New Orleans, Louisiana: American Institute of Aeronautics and Astronautics.

21. Danowski, C., and W. A. Wall. 2011. A monolithic approach to thermo-structure interaction in rocket nozzles. 4th European Conference for Aerospace Sciences (EUCASS). St. Petersburg.

22. Gerhold, T. 2002. Overview of the hybrid RANS code TAU. Notes Numer. Fluid Mechanics Multidisciplinary Design 89:81-92.

23. Schwamborn, D., T. Gerhold, and R. Heinrich. 2006. The DLR TAU-code: Recent applications in research and industry. In: European Conference on Computational Fluid Dynamics (ECCOMAS CFD). Eds. P. Wesseling, E. Onate, and J. Périaux. Delft: TU Delft.

24. Willems, S. 2007. Untersuchungen zur Widerstandsvorhersage mit dem numerischen Strömungslöser TAU. Student research paper. Aachen, German: RWTH.

25. Eisfeld, B., and O. Brodersen. 2005. Advanced turbulence modelling and stress analysis for the DLR-F6 configuration. 23rd AIAA Applied Aerodynamics Conference. Toronto, Ontario: American Institute of Aeronautics and Astronautics.

26. Eisfeld, B. 2010. Reynolds stress modelling for complex aerodynamic flows. In: European Conference on Computational Fluid Dynamics, ECCOMAS CFD. Eds. J. C. F. Pereira, and A. Sequeira. Lisbon. 1-11. 